\title{
Potential Bacterial Antagonists from Cowshed Air for the Management of Fusarium Pathogens in Stored Rice
}

\section{Nayak $\mathrm{S}^{1 *}$, Samanta $\mathrm{S}^{2}$ and Swain $\mathrm{SS}^{1}$}

${ }^{1}$ Odisha Biodiversity Board (Forest and Environment Department, Government of Odisha) Regional Plant Resource Centre Campus, India

${ }^{2}$ Women Scientist-B (Department of Science and Technology, Government of India) ICARNational Rice Research Institute, India

*Corresponding author: Shubhransu Nayak, Odisha Biodiversity Board (Forest and Environment Department, Government of Odisha), Regional Plant Resource Centre Campus, Ekamrakanan, Nayapalli, Bhubaneswar-751015, Odisha, India, Tel: +91-9853831959; Email: shubhransu.crri@gmail.com

\section{Abstract}

Rice is the principal staple food for more than half population of earth which is infested by many pathogens including Fusarium. Numbers of Fusarium species are responsible for causing pathogenic implications in rice like bakanae, rot, blight, etc. Majority of them produce mycotoxins which are responsible for human and animal toxicity and the cause of cancer disease. Adoption of biological control methods utilizing microbial antagonists might be an eco-friendly option. Bacterial species including Bacillus species have been isolated from various sources for utilisation as biocontrol agents to combat crop pathogens. Cow dung and the cow shed air have been a good source of such antagonistic bacteria. Hence, in the current study eighteen bacteria (BC1 to BC18) including Bacillus species have been isolated from cow shed air and paddy seeds stored in cowshed of Odisha, India. Bacteria isolated from domestic cowshed showed excellent inhibitory capacity than those of commercial cowshed against pathogenic Fusarium F90 and pathogenic as well as fumonisin producing Fusarium F55. Non-fumonisin producer Fusarium F90 was inhibited relatively with higher degree by all the antagonistic bacteria even it was completely suppressed by BC6 after three days of interaction. Paddy seeds stored in cowshed were found to be saturated with cowshed antagonistic bacteria. These bacterial antagonists hold potential to be utilized as Biological Control Agents (BCA) for safeguarding rice production. Investigation on more number of bacterial species from more cowsheds will definitely give more insights in the pattern and mode of inhibition.

Keywords: Bacillus; Rice; Fusarium, Fumonisin; Cowshed

Abbreviations: BCA: Biological Control Agents; PDNA: Potato Dextrose Nutrient Agar Media; ISR: Induced Systemic Resistance; IARC: International Agency for Research on Cancer.

\section{Introduction}

A number of pathogenic fungi infect rice before harvest and during storage conditions. Majority of these storage fungi belong to Aspergillus and Fusarium species in addition to number of other species like Alternaria, Bipolaris, Chaetomium, Cladosporium, Curvularia, Microdochium, Monilia, Mucor, Nakataea, Nigrospora, Penicillium, Pestalotia, Poma, Rhozoctonia, Rhizopus, etc. Numerous studies have indicated the presence of genetically diverse pathogenic and mycotoxigenic Fusarium species in stored rice grains 


\section{Open Access Journal of Microbiology \& Biotechnology}

of Europe, America, Africa, Asia and India [1-7]. Various species of Fusarium produce number of mycotoxins, most prevalent among them are fumonisins, moniliformin, zearalenone and trichothecenes (deoxynivalenol, nivalenol, T-2/HT-2 toxin, diacetoxyscirpenol) [8]. The International Agency for Research on Cancer (IARC) evaluated 'Fumonisin B1' as Group 2B possible carcinogen to humans causing in vivo nephrotoxicity and hepatotoxicity [9]. In addition to that, Fusarium infection may lead to various pathogenic implications in rice like bakanae disease, seed discoloration, rice spikelet rot disease, head blight, sheath rot complex, etc [10-13]. Application of synthetic fungicides to control the Fusarium infestation may lead to environmental and as well as human and animal health issues. Biological control methods utilizing microbial antagonists might be an effective and sustainable approach.

Various native bacterial species especially belonging to Bacillus species have been found be very effective against both pathogenic and toxigenic Fusarium species [14-18]. These Bacillus species have been isolated from soil and other agro-ecosystems which is a very common source. Many such Bacillus bacteria have been isolated from cowshed air and from rice seeds stored in cowshed environment which could control the vegetative growth of aflatoxigenic Aspergillus flavus and other pathogenic fungi $[18,19]$. However, no study has evaluated the antagonistic potential of Bacillus species and other bacteria from cowshed environment for the biological control of toxigenic and pathogenic Fusarium species in rice. Hence, the current investigation was carried out to isolate and evaluate 18 bacterial species from various cowsheds of Odisha, India for their effectiveness to control the growth of pathogenic and fumonisin producing Fusarium fungi.

\section{Materials and methods}

\section{Isolation of Antagonistic Bacterial Strains}

Bacterial antagonists were isolated from the cowshed environment from Bhadrak, Balasore and Cuttack districts of Odisha India. Both domestic cowshed and Commercial Goshala were explored. Sampling was carried out from two sources: from the cowshed air and from rice/paddy stored inside cowshed. Bacteria from cowshed air were isolated following passive air sampling method by exposing Potato Dextrose Nutrient Agar media (PDNA) plates to cattle shed air for one minute and then incubating at $30^{\circ} \mathrm{C}$ for 24 hours $[18,19]$. The bacteria associated with seeds or grains were isolated by blotter method [20]. After surface sterilization by $1 \% \mathrm{NaOCl}$ (Sodium hypochlorite) samples were plated on sterilised blotting paper. The bacterial colony appeared in the culture plate and blotter plate were then isolated and maintained as pure culture at Crop Protection Division of ICAR- National (Central) Rice Research Institute, India. Efficient Bacterial strains were identified by molecular method with sequence match of 16S RNA in the NCBIBLAST and the 16s RNA sequences were submitted to NCBI GenBank.

\section{Fusarium Isolates}

The two pathogenic Fusarium isolates F55 and F90 used in the current study were obtained from Crop Protection Division of ICAR-National (Central) Rice Research Institute, India. Both the pathogen strains have been isolated from infected discoloured rice seeds/grains where F55 was fumonisin producer F90 did not have the genes for fumonisin production [9]. Total 18 bacterial isolates named as $\mathrm{BC} 1$ to $\mathrm{BC} 18$ have been investigated for their antagonistic potential in the current study.

\section{Evaluation of Antagonistic Activity}

Eighteen bacterial isolates viz. BC1 to BC18were cultivated in $50 \mathrm{ml}$ LB Broth (DIFCO) for six hours in a shaker at $250 \mathrm{rpm}$ at $37^{\circ} \mathrm{C}$; The cultural broth was mixed properly with luke worm PDNA@100 $\mu \mathrm{l} / 15 \mathrm{ml}$ media. Later on this media was inoculated with test fungal isolate (s) F55 and F90. Untreated control and four replicates of each treatment were maintained in this study. The plates were incubated at $30^{\circ} \mathrm{C}$ and periodic colony growth was recorded.

The inhibition percentage in terms of inhibition of colony area was determined as follows:

[(A of untreated control - A of treatment) / A of control] $\times$ 100

Colony area $\mathrm{A}=\pi \mathrm{r}^{2}$

All statistical analysis was carried out by MS Excel application of MS Office.

\section{Results}

Total 18 bacterial isolates $\mathrm{BC} 1$ to $\mathrm{BC} 18$ were evaluated for their antagonistic activity against Fusarium pathogens F55 and F90. The passport data of bacterial antagonists is presented in Table 1. BC1 to BC4 were isolated from cowshed air of Bhadrak district by passive air sampling method, BC4 to BC8 were isolated from paddy seeds stored in cowshed of Balasore district and BC 9 to BC18 were isolated from cowshed air of Commercial cowshed (Gopal Krushna Gosala) of Cuttack district of Odisha. Figure 1 shows the various cowshed sampling sites and appearance of bacterial colonies on PDNA culture plates after passive air sampling and incubation. Sequence alignment of 16s RNA in earlier studies by Nayak, et al. [19] has identified BC1 and BC2 as Bacillus 
amyloliquefaciens, BC3 and BC6 as Bacillus subtilis, BC5 as Bacillus vallismortis and BC7 as Bacillus amyloliquefaciens sub sp.planta.

\begin{tabular}{|c|c|c|c|}
\hline $\begin{array}{c}\text { Isolate } \\
\text { ID }\end{array}$ & $\begin{array}{c}\text { NCBI GenBank } \\
\text { Accession no. }\end{array}$ & Identified organism & Source of isolation \\
\hline BC1 & JF304104 & Bacillus amyloliquefaciens & Indoor air of Cow shed located in Bhadrak district of Odisha, India \\
\hline BC2 & JF304105 & Bacillus amyloliquefaciens & Indoor air of Cow shed located in Bhadrak district of Odisha, India \\
\hline BC3 & JF304106 & Bacillus subtilis & Indoor air of Cow shed located in Bhadrak district of Odisha, India \\
\hline BC4 & - & Not identified & Indoor air of Cow shed located in Bhadrak district of Odisha, India \\
\hline BC5 & JQ753710 & Bacillus vallismortis & $\begin{array}{c}\text { Dehusked paddy samples stored in cowshed, collected from } \\
\text { Balasore district of Odisha, India }\end{array}$ \\
\hline BC6 & JF304107 & Bacillus subtilis & $\begin{array}{c}\text { Dehusked paddy samples stored in cowshed, collected from } \\
\text { Balasore district of Odisha, India }\end{array}$ \\
\hline BC7 & JQ753711 & $\begin{array}{c}\text { Bacillus amyloliquefaciens } \\
\text { sub sp.Planta. }\end{array}$ & $\begin{array}{c}\text { Dehusked paddy samples stored in cowshed, collected from } \\
\text { Balasore district of Odisha, India }\end{array}$ \\
\hline BC8 & - & Not identified & $\begin{array}{r}\text { Dehusked paddy samples stored in cowshed, collected from } \\
\text { Balasore district of Odisha, India }\end{array}$ \\
\hline BC9 - & - & Not identified & $\begin{array}{c}\text { Indoor air of Cow shed in a dairy farm (Goshala) located in Cuttack } \\
\text { district of Odisha, India }\end{array}$ \\
\hline
\end{tabular}

Table 1: Passport data of bacteria isolated from cowshed environments.
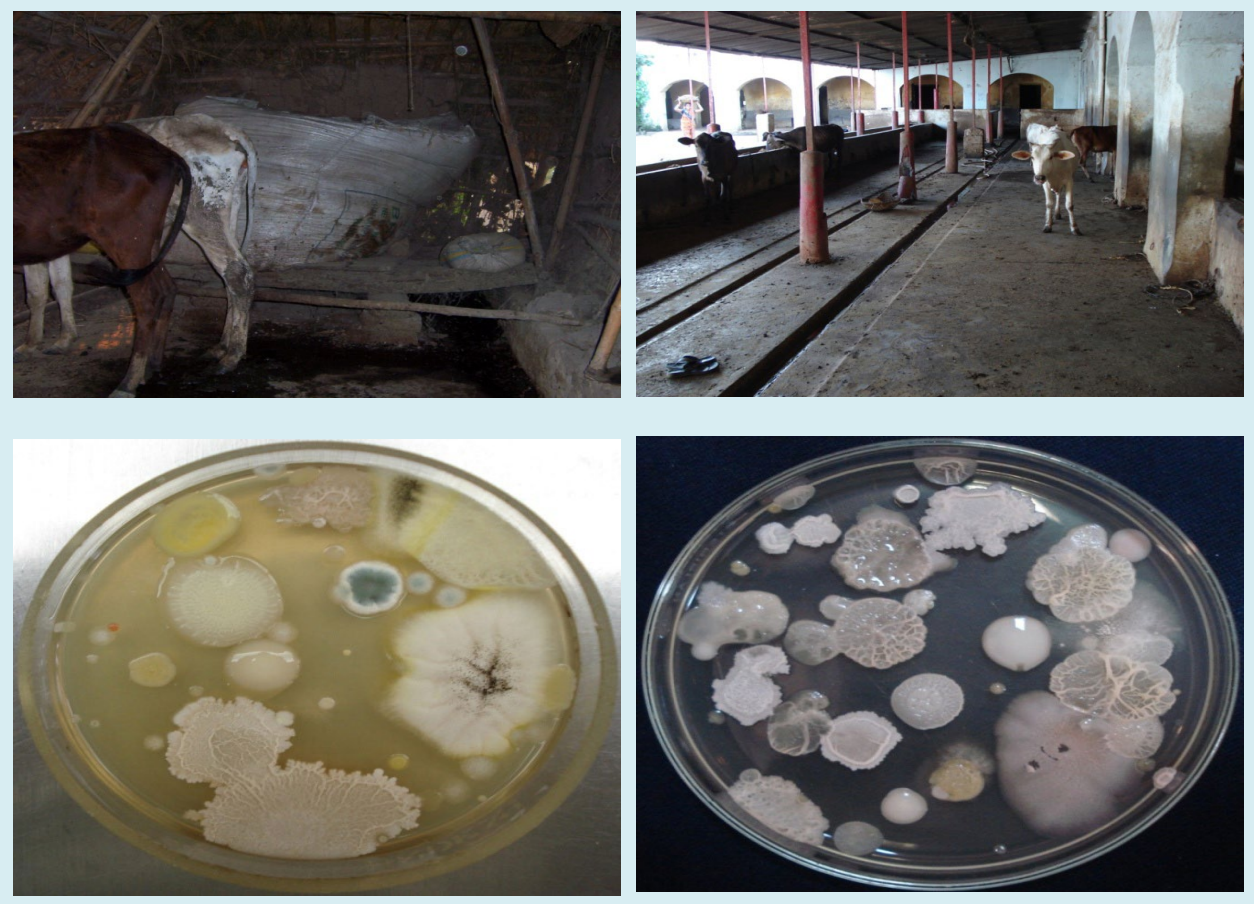

Figure 1: A-Paddy stored in cowshed, B-Commercial cowshed (Goshala), C \& D-Appearance of bacterial colonies on PDNA plates after exposure in cowshed environment. 


\section{Open Access Journal of Microbiology \& Biotechnology}

All the Cow shed bacteria (BC1 to BC18) tested here were found to be effective to control the vegetative growth of pathogenic and fumonisin producing Fusarium F55 and F90 (Table 2 \& Figure 2). Isolate $\mathrm{BC} 1, \mathrm{BC} 2, \mathrm{BC} 3, \mathrm{BC} 4, \mathrm{BC}$, BC6, BC7 and BC 8 could consistently inhibit the growth of F55 \& F90 in vitro where more than $90 \%$ reduction in 'area of colony' of test fungus $\mathrm{F} 55$ was observed. The impact of BC9, BC12, BC13, BC17 and BC18 on F55 was not significantly different. About $39.8 \%$ to $60.6 \%$ inhibition in colony area of Fusarium isolate F55 by eight cow shed bacteria BC 11 to BC18 was observed (Table 2).

\begin{tabular}{|c|c|c|c|c|c|c|}
\hline \multirow{2}{*}{ Bacterial isolates } & \multicolumn{3}{|c|}{ Inhibition of F55 } & \multicolumn{3}{c|}{ Inhibition of F90 } \\
\cline { 2 - 7 } & Day-1 & Day-2 & Day-3 & Day-1 & Day- 2 & Day-3 \\
\hline BC-1 & $96.4 \pm 0.7$ & $96.0 \pm 0.3$ & $96.7 \pm 0.2$ & $95.4 \pm 0.0$ & $96.8 \pm 0.2$ & $98.9 \pm 0.1$ \\
\hline BC-2 & $98.4 \pm 0.5$ & $96.9 \pm 0.3$ & $98.1 \pm 0.0$ & $96.3 \pm 0.5$ & $95.9 \pm 0.2$ & $98.9 \pm 0.1$ \\
\hline BC-3 & $97.9 \pm 0.3$ & $96.9 \pm 0.3$ & $98.1 \pm 0.0$ & $97.2 \pm 0.4$ & $98.7 \pm 0.2$ & $99.6 \pm 0.0$ \\
\hline BC-4 & $97.9 \pm 0.3$ & $97.2 \pm 0.4$ & $97.5 \pm 0.3$ & $94.3 \pm 0.6$ & $95.2 \pm 0.5$ & $98.4 \pm 0.2$ \\
\hline BC-5 & $94.7 \pm 0.5$ & $91.7 \pm 0.7$ & $94.9 \pm 0.4$ & $93.1 \pm 0.6$ & $95.9 \pm 0.2$ & $98.3 \pm 0.1$ \\
\hline BC-6 & $94.2 \pm 0.5$ & $92.6 \pm 0.7$ & $95.6 \pm 0.1$ & $100.0 \pm 0.0$ & $100.0 \pm 0.0$ & $100.0 \pm 0.0$ \\
\hline BC-7 & $96.1 \pm 0.4$ & $97.4 \pm 0.2$ & $98.6 \pm 0.1$ & $96.3 \pm 0.9$ & $97.9 \pm 0.1$ & $99.4 \pm 0.0$ \\
\hline BC-8 & $96.8 \pm 0.4$ & $97.4 \pm 0.2$ & $98.2 \pm 0.1$ & $97.6 \pm 0.4$ & $98.9 \pm 0.1$ & $99.7 \pm 0.0$ \\
\hline BC-9 & $47.5 \pm 0.9$ & $38.5 \pm 0.3$ & $42.0 \pm 0.5$ & $26.1 \pm 0.4$ & $32.5 \pm 1.0$ & $69.3 \pm 0.7$ \\
\hline BC-10 & $82.6 \pm 0.9$ & $81.6 \pm 0.7$ & $87.8 \pm 0.5$ & $83.6 \pm 1.0$ & $90.4 \pm 0.8$ & $95.5 \pm 0.0$ \\
\hline BC-11 & $61.5 \pm 0.6$ & $61.7 \pm 0.6$ & $60.6 \pm 0.7$ & $32.8 \pm 0.2$ & $48.8 \pm 0.7$ & $77.4 \pm 0.0$ \\
\hline BC-12 & $60.5 \pm 0.4$ & $58.0 \pm 0.7$ & $42.5 \pm 0.3$ & $39.1 \pm 0.8$ & $47.6 \pm 0.7$ & $67.4 \pm 0.5$ \\
\hline BC-13 & $44.3 \pm 0.5$ & $53.7 \pm 1.0$ & $44.6 \pm 0.4$ & $43.7 \pm 0.8$ & $50.0 \pm 0.6$ & $82.3 \pm 0.7$ \\
\hline BC-14 & $60.5 \pm 0.4$ & $59.3 \pm 0.7$ & $59.8 \pm 0.5$ & $38.0 \pm 0.2$ & $54.5 \pm 0.6$ & $85.6 \pm 0.3$ \\
\hline BC-15 & $77.9 \pm 0.1$ & $49.4 \pm 0.5$ & $66.2 \pm 0.7$ & $70.9 \pm 0.4$ & $38.7 \pm 0.9$ & $65.0 \pm 1.0$ \\
\hline BC-16 & $60.3 \pm 0.7$ & $43.4 \pm 0.5$ & $53.8 \pm 0.8$ & $70.6 \pm 0.7$ & $43.4 \pm 0.7$ & $79.0 \pm 0.8$ \\
\hline BC-17 & $49.1 \pm 0.8$ & $41.0 \pm 1.0$ & $40.1 \pm 0.3$ & $20.7 \pm 0.4$ & $41.6 \pm 0.9$ & $80.1 \pm 0.4$ \\
\hline BC-18 & $34.6 \pm 0.7$ & $31.7 \pm 0.9$ & $39.8 \pm 0.3$ & $13.9 \pm 0.2$ & $27.8 \pm 0.4$ & $68.3 \pm 0.8$ \\
\hline & & & & LSD at $p<0.05$ is 1.477 \\
\hline & LSD at $\mathrm{p}<0.05$ is 1.49 & & LSD at $\mathrm{p}<0.01$ is 1.952 \\
\hline
\end{tabular}

Table 2: Inhibition of fumonisin producing and pathogenic Fusarium by cowshed associated bacteria. Inhibtion shown in terms of colony area.

Similar trends were observed in antagonistic activity of cowshed bacteria against Fusarium isolate F90. However, degree of growth inhibition by all bacterial antagonists was more in case of F90 than F55 (Figure 3). BC6 was found to be the most effective against F90 amongst all the bacterial antagonists as the culture broth of BC6 could completely suppress the mycelia growth of F90 consistently for three days of interaction. Under same circumstances, about $95.6 \%$ inhibition of 'colony area' was achieved by BC6 against F55 (Table 2). Cow shed bacteria BC7 was almost evenly effective against both of the Fusarium isolates where $98.6 \%$ and $99.4 \%$ inhibition in colony area was observed against F55 and $\mathrm{F} 90$ respectively till third day of interaction. 


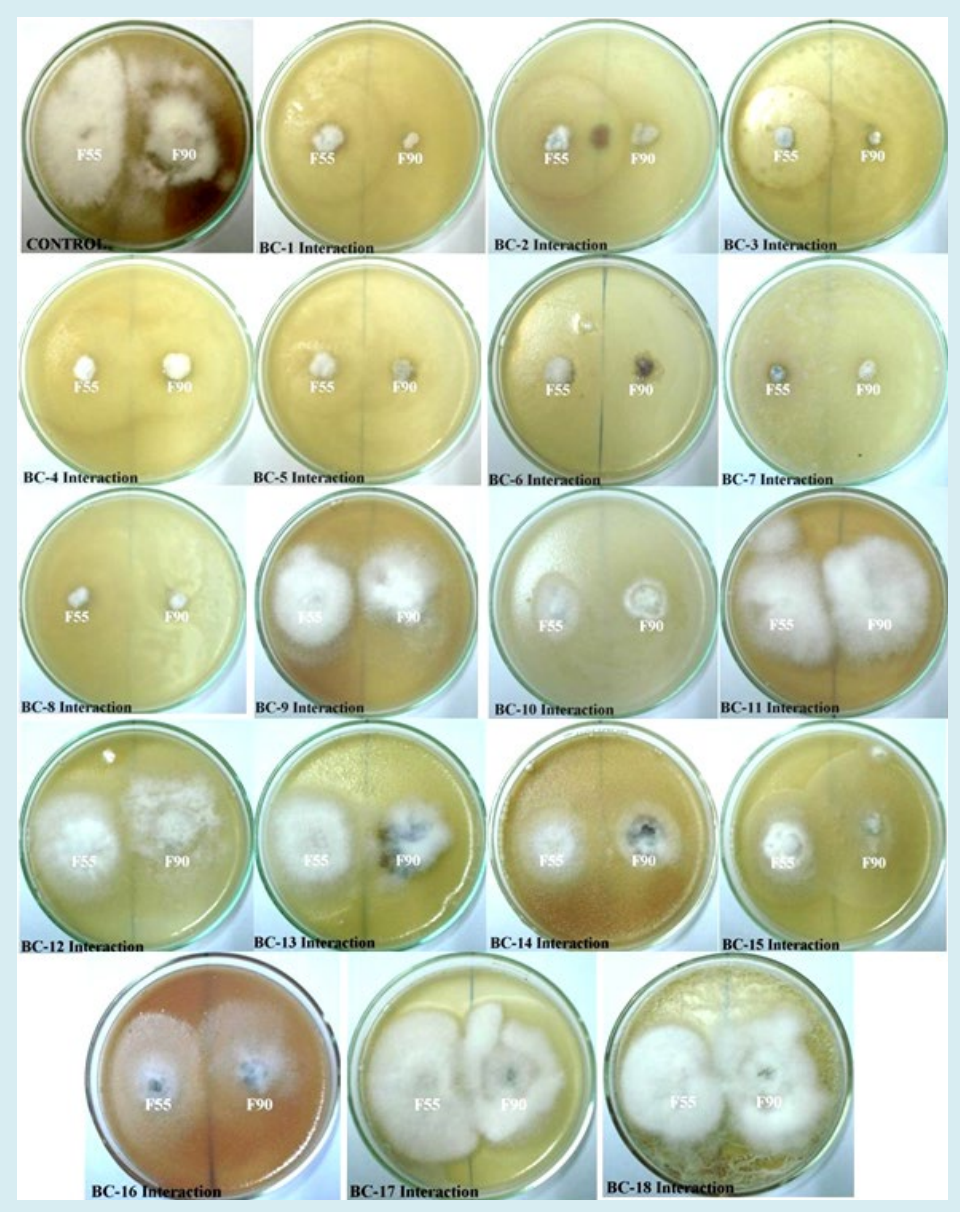

Figure 2: Inhibition of mycelia growth of Fusarium isolates F55 and F90 by the culture broth of bacterial antagonists isolated from cow shed.

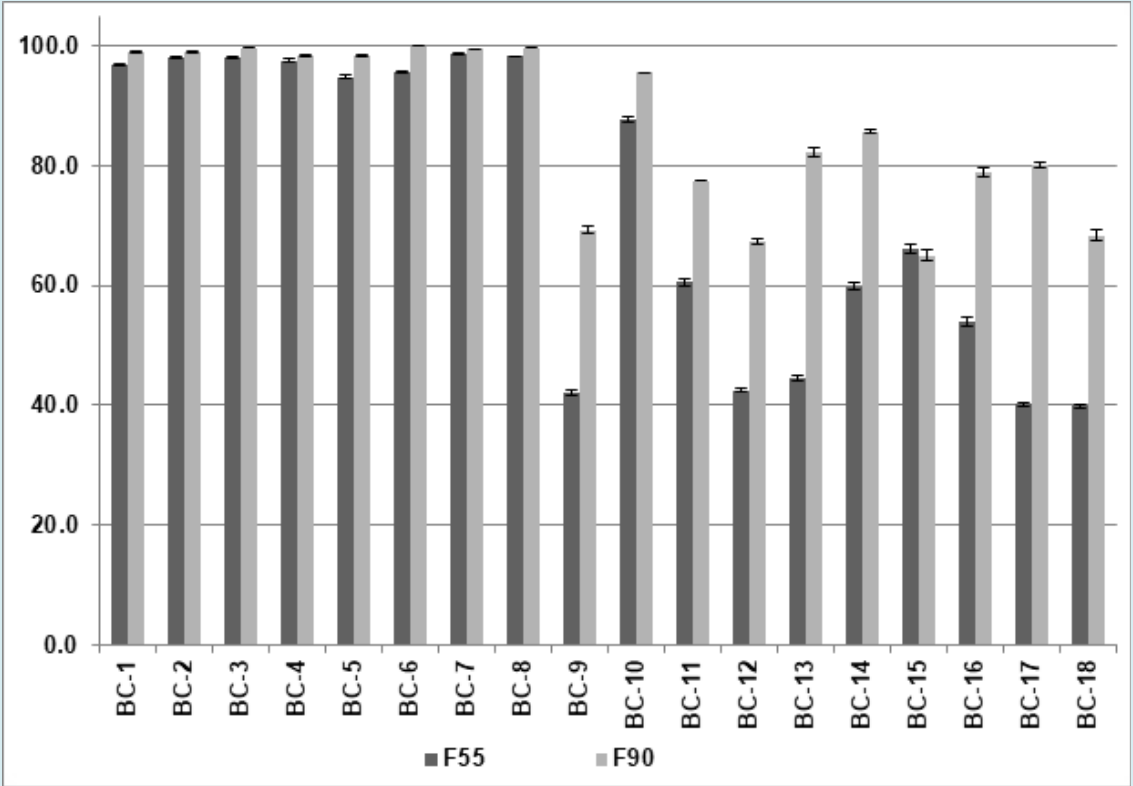

Figure 3: Growth inhibition of Fusarium isolates F55 and F90 by culture broth of Cow shed bacteria. 


\section{Open Access Journal of Microbiology \& Biotechnology}

Inhibition in terms of colony area is shown

The inhibition percentage was determined as follows:

[(A of untreated control - A of treatment)/ A of control $] \times 100$

Colony area $A=\pi r^{2}$

\section{Discussion}

Eighteen bacterial antagonists isolated from cowshed environment have been evaluated against pathogenic and fumonisin producing Fusarium species F55 and F90 in the currentinvestigation. All the strains showed their antagonistic effect with varied degree of efficiency. Bacillus species, as a group, offer several advantages over other bacteria for protection against pathogens because of their ability to form endospores and the broad-spectrum activity of their antibiotics [14]. There are numerous reports of Bacillus spp. which repressed Fusarium pathogens causing yield loss and grain deterioration by production of fuminisin mycotoxins in rice and other crops. A B. subtilis strain SG6 exhibited a high antifungal effect on the mycelium growth, sporulation and mycotoxin production of $F$.graminearum with the inhibition rate of $87.9 \%, 95.6 \%$ and $100 \%$, respectively. The antifungal activity of SG6 could be associated with the coproduction of chitinase, fengycins and surfactins. Surfactins could synergistically impact the anti-fungal activity of other lipopeptides [15]. Ajilogba, et al. [16] evaluated Four Bacillus spp. B. amyloliquefaciens, B. cereus, B. pumilus and B. subtilis for biocontrol activities against Fusarium solani in vitro where inhibition percentage as high as 95\% could be achieved. These antagonistic Bacillus species have often been isolated from similar niches as of their host plant. Even species like Bacillus halotolerans isolated from contrasting niches have been found as 'Plant Warden' against wide range of Fusarium phytopathogens [17]. Inhibition percentage shown by most of the bacteria included in this study was at par with all these observations where inhibition as high as $100 \%$ has been achieved by BC6. Cow dung has served as a source for the presence of antifungal biocontrol agents including Bacillus species. Many Bacillus species isolated from cow dung have also been reported to possess antagonistic activity against many plant pathogens including Fusarium. Subsequently, the cow shed air which is saturated with these useful Bacillus bacteria might also be a selective source for exploration of antagonistic bacteria [18]. However, no study has been conducted elsewhere to explore this possible source for the isolation of antagonistic bacteria against Fusarium pathogens infecting rice and producing fumonisin mycotoxin.

In the current investigation high degree of inhibition (100\% in some cases) was shown by all the bacteria isolated from cowshed environment. Even, the paddy seeds stored in the cow shed also found to be enriched with Bacillus bacteria which became seed borne. BC5 to BC8 isolated from paddy seeds could restrict the mycelia growth of both of the
Fusarium sp. where BC6 showed 100\% inhibition percentage towards F90. Other bacterial species isolated from the commercial cow shed Gopal Krishna Goshala, also exhibited reasonable antagonism to Fusarium but the inhibition was significantly less than that of bacteria (BC1 to BC8) isolated from domestic cow sheds. People in the rural area of Odisha, India generally keep indigenous breeds of cows in domestic cow sheds where as hybrid cow varieties are kept in the commercial cow sheds (Goshala). In the current investigation, higher antagonism to pathogenic and fumonisin producing Fusarium was obtained by the bacterial species isolated from domestic cow sheds than that of commercial cow shed. This observation indicated the presence of bacterial species having higher bioactivity in the cow dung of indigenous breeds and subsequently in the cow shed environment of domestic cow sheds. This observation holds a scope for the investigation of microflora in more number of domestic and commercial cows sheds to get in to conclusive evidence.

The current state of crop losses due to pathogenic diseases is alarming, with an estimated $8-40 \%$ of crop yield losses caused by plant pathogens worldwide. The impact of losses ranges from a modest reduction of plant-growth measurements to more serious damage leading to plant death and reduced yield. Fusarium species are globally important pathogens of agricultural plants, livestock and also humans and also produce a range of mycotoxins. Numerous mycotoxins produced by Fusarium species with the ability to cause diseases in plants and animals have been described in literatures [21]. In the past three decades, control strategies against this devastating plant pathogen have been based solely on fungicide application, which has resulted in longterm undesirable environmental pollution [22]. With the increase in awareness of the danger of chemical control applications, fungicides are beginning to take a back foot, with the use of biocontrol products being exploited. Among a variety of bacterial genera, species of Bacillus, Pseudomonas and Streptomyces have been widely used as BCA. Bacteria from cowshed in general and Bacillus species in particular have always held the potential to be ideal organism for biological control of plant pathogens. Bacillus species play a great role as bacterial antagonists to pathogens due to their ability to reproduce actively and their resistance to unfavorable environmental conditions. The species' antagonistic activities are associated with the production of metabolites with antibiotic properties. Particularly, volatile metabolites produced by these microorganisms also play an important role in the activation of plant defense mechanisms by triggering induced systemic resistance (ISR) in plants. In addition, plant host defense responses can also be activated during the production of metabolites by Bacillus species. As documented in the literature, Bacillus spp. also directly antagonize fungal pathogens by competing and depriving them of essential nutrients, by producing fungitoxic 


\section{Open Access Journal of Microbiology \& Biotechnology}

compounds $[23,24]$.

\section{Conclusion}

Eighteen bacteria isolated from the cow shed environment exhibited antagonistic activity towards pathogenic and fumonisin mycotoxins producing Fusarium. Bacillus species bacteria isolated from domestic cow shed air and paddy seeds kept in cow shed showed higher inhibitory capacity than bacteria isolated from commercial cow sheds. Various Fusarium species are responsible for causing diseases and mycotoxins production in rice and other crops. Hence, biocontrol strategies employing cowshed bacteria might be a potential option for safe guarding rice which is the principal food for more than half of world's population. Investigation of more numbers of cowshed bacteria might give more insights in to the distribution and pattern of biocontrol efficacy of the resident bacteria.

\section{References}

1. Sweets L (2018) Stored grain fungi. Agricultural Electronic Bulletin Board, University of Missouri Extension, CAFNR.

2. Bertuzzi T, Romani M, Rastelli S, Giorni P (2019) Mycotoxins and related fungi in Italian paddy rice during the growing season and storage. Toxins (Basel) 11(3): 151.

3. Tang EN, Ndindeng SA, Bigoga J, Traore K, Silue D, et al. (2019) Mycotoxin concentrations in rice from three climatic locations in Africa as affected by grain quality, production site, and storage duration. Food science \& nutrition 7(4): 1274-1287.

4. Nayak S, Dhua U, Samanta S, Chhotaray A (2014) Molecular detection and genetic characterisation of fumonisin producing Fusarium isolates from rice cultivars. International Journal of Agriculture, Environment and Biotechnology 7(4): 695-704.

5. Maheshwar PK, Moharram SA, Janardhana GR (2009) Detection of fumonisin producing Fusarium verticillioides in paddy (Oryza sativa L.) using polymerase chain reaction (PCR). Braz J Microbiol 40(1): 134-138.

6. Desjardins AE, Manandhar HK, Plattner RD, Manandhar GG, Poling SM, et al. (2000) Fusarium species from Nepalese rice and production of mycotoxins and gibberellic acid by selected species. Applied and Environmental Microbiology 66(3): 1020-1025.

7. Misra JK, Gergon EB, Mew TW (1995) Storage fungi and seed health of rice: a study in the Philippines. Mycopathologia 131(1): 13-24.
8. Nesic K, Ivanovic S, Nesic V (2014) Fusarial toxins: secondary metabolites of Fusarium fungi. Rev Environ Contam Toxicol 228: 101-120.

9. Nayak S, Dhua U, Chhotaray A, Samanta S, Sengupta C (2018) Genetic diversity of fumonisin producing Fusarium isolates from rice using PCR-RFLP of IGSrDNA region. Biodiversitas Journal of Biological Diversity 19(2): 571-576.

10. Bigirimana VDP, Hua GK, Nyamangyoku OI, Höfte $M$ (2015) Rice sheath rot: an emerging ubiquitous destructive disease complex. Front plant sci 6: 1066.

11. Kim Y, Kang IJ, Shin DB, Roh JH, Heu S, et al. (2018) Timing of Fusarium Head Blight infection in rice by heading stage. Mycobiology 46(3): 283-286.

12. Lei SUN, Wang L, Liu L, Hou Y, Xu Y, et al. (2019) Infection and colonization of pathogenic fungus Fusarium proliferatum in rice spikelet rot disease. Rice Science 26(1): 60-68.

13. Sunani SK, Bashyal BM, Kharayat BS, Prakash G, Krishnan $S G$, et al. (2020) Identification of rice seed infection routes of Fusarium fujikuroi inciting bakanae disease of rice. Journal of Plant Pathology 102(1): 113-121.

14. Cavaglieri L, Orlando JRMI, Rodríguez MI, Chulze S, Etcheverry M (2005) Biocontrol of Bacillus subtilis against Fusarium verticillioides in vitro and at the maize root level. Res Microbiol 156(5-6): 748-754.

15. Zhao Y, Selvaraj JN, Xing F, Zhou L, Wang Y, et al. (2014) Antagonistic action of Bacillus subtilis strain SG6 on Fusarium graminearum. PloS one 9(3): e92486.

16. Ajilogba CF, Babalola 00, Ahmad F (2013) Antagonistic effects of Bacillus species in biocontrol of tomato Fusarium wilt. Studies on Ethno-Medicine 7(3): 205216.

17. Slama HB, Hafsa Cherif-Silini, Ali CB, Mallique Q, Allaoua S, et al. (2019) Screening for Fusarium antagonistic bacteria from contrasting niches designated the endophyte Bacillus halotolerans as plant warden against Fusarium. Front Microbiol 9: 3236.

18. Nayak S, Dhua U, Samanta S (2020) Antagonistic activity of cowshed Bacillus sp. bacteria against aflatoxigenic and sclerotic Aspergillus flavus. Journal of Biological Control 34(1): 52-58.

19. Nayak S, Dhua U, Samanta S (2019) Cowshed Air Could Serve As A Source of Bacillus Sp. Bacteria for The Management of Rice Pathogens. Asian Journal of Microbiology Biotechnology and Environmental 


\section{Open Access Journal of Microbiology \& Biotechnology}

Sciences 21(S1): S91-S95.

20. Agarwal VK, Sinclair JB (1996) Principles of Seed Pathology, $2^{\text {nd }}(E d n)$, Lewis Publishers, CRC press, USA.

21. Antonissen G, Martel A, Pasmans F, Ducatelle R, Verbrugghe E, et al. (2014) The impact of Fusarium mycotoxins on human and animal host susceptibility to infectious diseases. Toxins (Basel) 6(2): 430-452.

22. Zhang YJ, Yu JJ, Zhang YN, Zhang X, Cheng CJ, et al. (2009) Effect of carbendazim resistance on trichothecene production and aggressiveness of Fusarium graminearum. Molecular Plant Microbe Interaction 22(9): 1143-1150.

23. Ntushelo K, Ledwaba LK, Rauwane ME, Adebo OA, Njobeh PB (2019) The mode of action of Bacillus species against Fusarium graminearum, tools for investigation, and future prospects. Toxins (Basel) 11(10): 606.

24. Khan N, Maymon M, Hirsch AM (2017) Combating Fusarium infection using Bacillus-based antimicrobials. Microorganisms 5(4): 75. 